OPEN ACCESS

Edited by:

VijayaKumar Sukumaran, Qatar University, Qatar

Reviewed by: Zhuoming Li,

Sun Yat-Sen University, China Rizwan Ahmed, Johns Hopkins University, United States

Nicola Maurea,

Istituto Nazionale Tumori IRCCS

"Fondazione G. Pascale", Italy

*Correspondence:

Mónica Gallego monica.gallego@ehu.eus

Specialty section: This article was submitted to Cardiovascular and Smooth Muscle Pharmacology,

a section of the journal Frontiers in Pharmacology

Received: 29 March 2021 Accepted: 15 June 2021 Published: 08 July 2021

Citation:

Gallego M, Zayas-Arrabal J, Alquiza A, Apellaniz B and Casis O (2021)

Electrical Features of the Diabetic

Myocardium. Arrhythmic and Cardiovascular Safety Considerations in Diabetes.

Front. Pharmacol. 12:687256. doi: 10.3389/fphar.2021.687256

\section{Electrical Features of the Diabetic Myocardium. Arrhythmic and Cardiovascular Safety Considerations in Diabetes}

\author{
Mónica Gallego*, Julián Zayas-Arrabal, Amaia Alquiza, Beatriz Apellaniz and Oscar Casis \\ Department of Physiology, Faculty of Pharmacy, University of the Basque Country UPVIEHU, Vitoria-Gasteiz, Spain
}

Diabetes is a chronic metabolic disease characterized by hyperglycemia in the absence of treatment. Among the diabetes-associated complications, cardiovascular disease is the major cause of mortality and morbidity in diabetic patients. Diabetes causes a complex myocardial dysfunction, referred as diabetic cardiomyopathy, which even in the absence of other cardiac risk factors results in abnormal diastolic and systolic function. Besides mechanical abnormalities, altered electrical function is another major feature of the diabetic myocardium. Both type 1 and type 2 diabetic patients often show cardiac electrical remodeling, mainly a prolonged ventricular repolarization visible in the electrocardiogram as a lengthening of the QT interval duration. The underlying mechanisms at the cellular level involve alterations on the expression and activity of several cardiac ion channels and their associated regulatory proteins. Consequent changes in sodium, calcium and potassium currents collectively lead to a delay in repolarization that can increase the risk of developing life-threatening ventricular arrhythmias and sudden death. QT duration correlates strongly with the risk of developing torsade de pointes, a form of ventricular tachycardia that can degenerate into ventricular fibrillation. Therefore, QT prolongation is a qualitative marker of proarrhythmic risk, and analysis of ventricular repolarization is therefore required for the approval of new drugs. To that end, the Thorough QT/QTc analysis evaluates QT interval prolongation to assess potential proarrhythmic effects. In addition, since diabetic patients have a higher risk to die from cardiovascular causes than individuals without diabetes, cardiovascular safety of the new antidiabetic drugs must be carefully evaluated in type 2 diabetic patients. These cardiovascular outcome trials reveal that some glucose-lowering drugs actually reduce cardiovascular risk. The mechanism of cardioprotection might involve a reduction of the risk of developing arrhythmia.

Keywords: ion channels, currents, cardiac, arrhythmia, antidiabetics, CVOT, TQT

\section{INTRODUCTION}

Diabetes affected 422 million adults in 2014 (WHO, 2021), but the incidence and the associated socio-sanitary cost are steadily rising. Diabetes is a chronic metabolic disease characterized by hyperglycemia in the absence of treatment. Type 1 diabetes (T1D), caused by insufficient or no insulin production, is the less common form. Type 2 diabetes (T2D) accounts for more than $90 \%$ of 
the cases and starts with insulin resistance, but later progresses towards various degrees of $\beta$-cell dysfunction. As a result, many type 2 diabetic patients may need exogenous insulin.

In the last decades, available pharmacologic approaches have significantly improved the life span and the quality of life of diabetic patients. However, over time, diabetes-associated complications have emerged. Among them, cardiovascular disease stands out because is the major cause of mortality and morbidity in diabetic patients. In fact, the Framingham study reported that patients with type 2 diabetes were twice as likely as healthy people to die from cardiovascular diseases (Kannel et al., 1974). Currently, due to the advances in diabetes management, many diabetic patients achieve good glycemic control. However, cardiovascular complications remain (Food and Drug Administration, 2008; Duckworth et al., 2009) and are still the leading cause of death (Preis et al., 2009; Xu and Rajaratnam, 2017).

Besides inducing cardiovascular disease, diabetes changes the myocardial structure leading to a cardiac dysfunction known as diabetic cardiomyopathy. Diabetic cardiomyopathy was first described by Rubler et al., in 1972 as heart failure in diabetics without hypertension, myocardial ischemia, congenital or valvular disease (Rubler et al., 1972). It is currently defined as a ventricular dysfunction in the absence of coronary artery disease or hypertension (Bugger and Abel, 2014). In fact, the Framingham study described the association between diabetes and cardiac hypertrophy independently from blood pressure (Kannel et al., 1974). Moreover, the Cardiovascular Health study (Lee et al., 1997) and the Strong Heart study (Devereux et al., 2000) confirmed the association between diabetes and increased left ventricular mass and wall thickness with compromised diastolic and systolic function. Different mechanisms have been proposed to promote the development of diabetic cardiomyopathy and damage the heart. These include cardiac insulin resistance; metabolic remodeling with abnormal free fatty acids metabolism and lipotoxicity; mitochondrial dysfunction with increased ROS production; accumulation of advanced glycation end products and collagen; abnormalities in calcium handling; pro-inflammatory responses; activation of the renin-angiotensin-aldosterone system and autonomic neuropathy with increased sympathetic activity (reviewed in Casis and Echevarria, 2004; Battiprolu et al., 2013; Bugger and Abel, 2014; Onay-Besikci, 2014; Grisanti, 2018; Jia et al., 2018; Palomer et al., 2018; Quagliariello et al., 2020).

Torsade de pointes (TdP) is a ventricular arrhythmia characterized by a change in the amplitude and a twisting of the QRS complexes around the isoelectric line in the electrocardiogram. TdP usually ends spontaneously, but in some cases may degenerate into lethal ventricular fibrillation. Long QT syndrome is an inherited or drug-induced arrhythmia syndrome characterized by a prolongation of the QT interval (Sanguinetti and Tristani-Firouzi, 2006; Schwartz et al., 2012) that causes torsade de pointes, ventricular fibrillation and sudden death. Since TdP occurs in the setting of prolonged QT intervals, QT duration and heart rate-corrected QT duration (QTc) have become qualitative markers of proarrhythmic risk. The electrocardiogram of both type 1 and type 2 diabetic patients

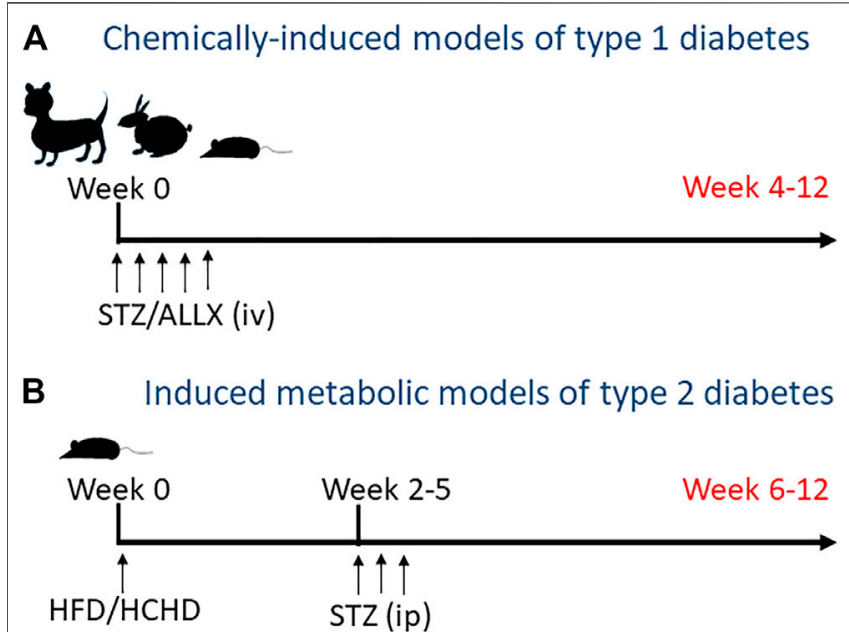

C Genetic models of type 2 diabetes

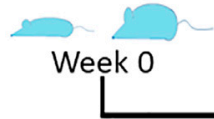

Week 4-12

FIGURE 1 | Animal models for diabetes. (A) Type 1 diabetes is induced by intravenous injection of streptozotocin or alloxane to kill pancreatic beta cells. Depending on the species, one or more consecutive injections of the toxic are required. (B) Metabolic models for type 2 diabetes include dietinduced insulin resistance followed by mild to medium pancreatic toxicity. Animals are fed with high fat and/or high carbohidrate diet (HFD and HCHD, respectively) for some weeks to generate insulin resistance and then receive one or more intraperitoneal injections of low dose streptozotocin to reduce beta cell mass. (C) Genetically hyperinsulinemic and/or hyperglycemic animals, lean and obese, spontaneously develop diabetes over time.

often shows prolonged QT (Bellavere et al., 1988; Chambers et al., 1990; Jermendy et al., 1990; Ewing et al., 1991; Veglio et al., 2000; Brown et al., 2001; Ninkovic et al., 2016), which increases the risk of ventricular arrhythmia (Tse et al., 2016; Hegyi et al., 2019). At the cellular level, diabetes lengthens the cardiac action potential duration due to changes in the expression and electrophysiological properties of various ion channels (Lengyel et al., 2007; Torres-Jacome et al., 2013; Gallego and Casis, 2014).

In addition, arrhythmogenesis in diabetes might be amplified by other factors like autonomic dysregulation (Jermendy, 2003; Spallone et al., 2011; Chen et al., 2019), inflammation (Karam et al., 2017) and the presence of comorbidities such as hypertension (Yiu and Tse, 2008). This review focuses on the electrical characteristics of the diabetic myocardium, such as reduced conduction velocity and prolonged ventricular repolarization. Since these alterations may increase the risk of arrhythmia, evaluating the proarrhythmic risk of new drugs is very relevant for the case of glucose-lowering drugs.

Since 2005, potential proarrhythmic risk must be evaluated for the approval of any new drug, including new anti-hyperglycemic drugs. Currently, the Thorough QT/QTc (TQT) studies are performed with premarketing drugs in order to exclude those that prolong the QT interval (ICH E14). At the same time, 
concerns about cardiovascular risk in diabetic patients has guided the policy of the regulatory agencies to establish the safety of new glucose-lowering drugs. Therefore, cardiovascular outcome trials (CVOTs) that evaluate specific cardiovascular endpoints are being conducted on type 2 diabetic patients (Goldfine, 2008). Furthermore, the information is being incorporated into the standards of medical care (Scheen, 2020).

In the preclinical setting, animal models, mainly rodents, but also guinea pigs, rabbits and dogs, are commonly used for the study of the diabetic heart. Currently, there are many different animal models for T1D and T2D (Figure 1). These have been extensively reviewed, and include spontaneous, transgenic as well as surgically, chemically and diet-induced models (Masiello, 2006; King, 2012; Al-awar et al., 2016; King and Bowe, 2016). Most of our knowledge regarding cardiac electrical remodeling in diabetes derives from studies with animal models of T1D (Magyar et al., 1992; Shimoni et al., 1994; Casis et al., 2000; Lengyel et al., 2007; Lengyel et al., 2008). Streptozotocin (STZ) and alloxane are glucose analogues that destroy pancreatic $\beta$-cells (Lenzen, 2008) and have been, for decades, the choice for inducing experimental diabetes because the procedure is simple and reliable. T2D has a different origin and pathophysiology. In humans, it starts with insulin resistance and eventually there is a loss of functional $\beta$-cells and hyperglycemia. In order to recapitulate this situation, a number of animal models have been generated using different strategies. Among them are the leptin-receptor deficient obese mice $\left(\operatorname{Lepr}^{\mathrm{db} / \mathrm{db}}\right)$, the non-obese Goto-Kakizaki (GK) rat with defective $\beta$-cells, the obese Otsuka Long Evans Tokushima Fat rat (OLETF) or the Zucker diabetic fatty rats (ZDF). In addition, metabolic models that combine high fat and/or highcarbohydrate diet with an intraperitoneal low-dose of STZ (Ionut et al., 2010; Podell et al., 2017) are becoming popular. Progressive feeding on high caloric food leads to glucose intolerance and insulin resistance, whereas STZ provides the loss of functional beta cell mass required establishing diabetes.

In the following section, we will discuss the electrical characteristics of the diabetic myocardium that may eventually increase the risk of arrhythmia: from changes in the electrocardiogram and the action potential, to altered behavior of sodium, calcium and potassium channels. Then, we will examine the proarrhythmic safety of antidiabetic drugs and the recommended treatments for type 2 diabetic patients at cardiovascular risk.

\section{CARDIAC ELECTRICAL REMODELING}

\section{Alterations in the Cardiac Conduction System in Diabetes}

Although diabetic patients frequently have increased heart rate (Ziegler et al., 2008), diagnosis of bradyarrhythmia and the need for pacemaker treatment are also more frequent in type 2 diabetic patients than in control subjects (Rautio et al., 2020). Among the diabetes-induced electrical disturbances, there is a nodal dysfunction that may be related to autonomic dysregulation. In line with this, leptin-receptor deficient $\mathrm{db} / \mathrm{db}$ mice showed reduced sinus node recovery time and relative autonomic denervation that increased the risk of developing arrhythmia (Soltysinska et al., 2014). On the other hand, there are intrinsic abnormalities in the sinoatrial node that affect the generation and conduction of electricity. For example, the non-obese type 2 diabetic Goto-Kakizaki (GK) rats had a reduced expression of pacemaker channels and connexins. Among others, genes encoding connexins $\mathrm{Cx} 40, \mathrm{Cx} 43$, and $\mathrm{Cx} 45$, as well as the hyperpolarization-activated cyclic nucleotide-gated channel 4 (HCN4) that drives the funny current $\mathrm{I}_{\mathrm{f}}$, were downregulated (Howarth et al., 2018).

Some diabetic patients display slow ventricular depolarization that is visible in the electrocardiogram as an increase in QRS duration (Singleton et al., 2020). Reduced expression of HCN4, connexins and ion channels has also been confirmed in different regions of the cardiac conduction system in the STZ models of T1D (Howarth et al., 2007; Watanabe et al., 2012; Zhang et al., 2019).

Fibroblasts are the most abundant non-cardiomyocyte cells in atria and ventricles. Cardiac fibroblasts can undergo an activation process and differentiate to myofibroblasts that express connexins $\mathrm{Cx} 43$ and $\mathrm{Cx} 45$. Through these gap junction proteins, myofibroblasts directly interact with cardiomyocytes modulating their electrophysiological behavior and reducing cardiac impulse conduction (Miragoli et al., 2006). Diabetes favors the phenotype switch to myofibroblasts in the heart. Thus, differentiation to myofibroblasts is increased in hearts from STZ-treated and Zucker diabetic rats, which are animal models of T1D and T2D, respectively (Li et al., 2012a; Fowllkes et al., 2013).

Prior to the development of fibrosis, diabetes can induce a lateralization of connexin 43 proteins that may impair electrical coupling. Although normal baseline conduction velocity was observed in diabetic rats one to 2 weeks after STZ injection, this normal functioning might be sustained by a robust ventricular conduction reserve. However, under challenging conditions like elevated potassium or ischemia, diabetic ventricles showed larger conduction times compared to controls (Nygren et al., 2007; Rahnema et al., 2011). Furthermore, overt impaired conduction velocity may develop as diabetes progresses. In this sense, long-term type 1 diabetic rabbits without cardiac fibrosis had decreased conduction already in basal conditions. Again, stressing the heart with hypo or hyperkalemia further slowed the velocity. A mechanism responsible might be the diabetes-induced reduction in the cardiac sodium current, as reported by electrophysiological techniques and mathematical modeling (Stables et al., 2014).

\section{Atrial Fibrillation}

Diabetes is an independent risk factor for atrial fibrillation (AF) and diabetic patients have one-third greater risk of incidence of AF compared with unaffected individuals (Huxley et al., 2012). Although the underlying pathophysiological mechanisms are not completely understood, diabetes-induced atrial remodeling shares some mechanisms with diabetic cardiomyopathy. Atrial autonomic dysregulation, oxidative stress, fluctuations of glucose levels and structural and electrical remodeling contribute to the development of arrhythmia (Goudis et al., 2015; Wang et al., 

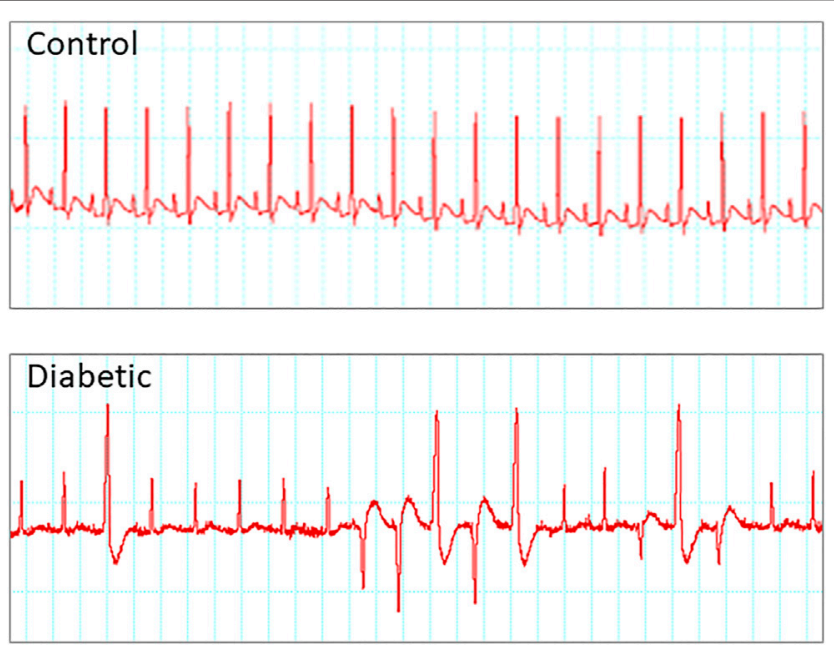

FIGURE 2 | Diabetes is a substrate for developing arrhythmia. Example of electrocardiograms recorded from control and type 2 diabetic rats upon stimulation with caffeine plus dobutamine. Only diabetic animals develop arrhythmia under cardiac challenge.

2019). For instance, the above mentioned diabetes-induced differential expression of conexins, that affects action potential conduction, might contribute to the development of atrial fibrillation (Watanabe et al., 2012). Regarding the electrical remodeling, diabetic Zucker obese rats with higher susceptibility to AF showed prolonged atrial action potential duration due to a reduction of the ultrarapid delayed rectifier and transient outward repolarizing currents $\left(\mathrm{I}_{\text {kur }}\right.$ and $\left.\mathrm{I}_{\text {to }}\right)$ along with a reduction of the corresponding channel forming proteins (Fu et al., 2019).

\section{Prolonged QT Interval Duration}

The most-studied electrical alteration of the diabetic myocardium is prolonged ventricular repolarization. Diabetes-induced lengthening of QT and QTc intervals associates with higher risk of developing ventricular arrhythmias and sudden cardiac death (Figure 2). Prolonged QTc was first reported in individuals with diabetic neuropathy (Bellavere et al., 1988; Chambers et al., 1990; Jermendy et al., 1990; Ewing et al., 1991) and later, it was also observed in newly diagnosed type 2 diabetic patients with no apparent complications (Naas et al., 1998). It is difficult to estimate the prevalence of longer QTc among diabetics. The different characteristics of the cohorts in each study and the formula used to adjust the QT for heart rate (Bazett, Fridericia, Hodges, others) lead to heterogeneous results, with prevalence estimates ranging from 30 to $66 \%$ (Veglio et al., 2002; Kumar et al., 2004; Li et al., 2012b; Cox et al., 2014; Lu et al., 2017). In these studies, recruited participants usually exhibited diabetes with several years of duration and therefore received antidiabetic medication. Metformin is the first choice to start glycemic control and many patients require additional drugs over time (Ferrannini and DeFronzo, 2015). Most prevalence studies do not differentiate subjects on monotherapy from those on combined therapy, but the fact is that antidiabetic medication does not seem to be efficient to restore normal QTc values.
Another parameter that analyzes the repolarization is the QT dispersion or QTd, which reflects the difference between the longer and the shorter QT interval duration in the 12 leads electrocardiogram. An increase in the QTd is typically associated to an increased predisposition to ventricular arrhythmias. Diabetic patients show increased QTd and heart-rate corrected QT dispersion (QTdc) compared to non-diabetic subjects in the absence of other cardiovascular pathologies. Although the prevalence of severe prolonged QTc $(>500 \mathrm{~ms})$ and QTd (>80 ms) is low (Ninkovic et al., 2016), the presence of concomitant cardiovascular abnormalities such as left ventricular hypertrophy or hypertension increased the QT dispersion in diabetes mellitus (Cardoso et al., 2001).

\section{ION CHANNELS AND CURRENTS IN THE DIABETIC MYOCARDIUM}

The basic electrical activity of the cardiac cells is an action potential consisting of a rapid depolarization phase followed by a repolarization phase with a plateau. In 1983, Fein et al. described for the first time a lengthening of the cardiac action potential duration (APD) in a rat model of T1D (Fein et al., 1983), an effect consistently confirmed in rodent and non-rodent models (Magyar et al., 1992; Casis et al., 2000; Lengyel et al., 2007; Torres-Jacome et al., 2013). Thus, the APD observed in animal models of diabetes correlates with the prolonged QTc duration and increased QTd found in diabetic patients. In addition, in ventricular myocytes isolated from diabetic rats APD prolongation was not homogeneous throughout the heart, and the effect was more pronounced in the endocardium than in the epicardium (Casis et al., 2000). Prolonged APD results from diabetes-induced alterations in the expression and behavior of several ion channels that conduct depolarizing (sodium and calcium) and repolarizing (potassium) currents (summarized in Figure 3).

\section{Alterations in the Sodium Current}

The protein Nav1.5, encoded by the SCN5A gene, is the cardiac isoform of the voltage-gated sodium channel, which is responsible for carrying the sodium current, or $\mathrm{I}_{\mathrm{Na}}$. Diabetic rabbits displayed a reduction in the density of the cardiac $\mathrm{I}_{\mathrm{Na}}$ although the Nav1.5 protein levels were not significantly reduced (Stables et al., 2014). However, in type 1 diabetic rats, as well as in culture cells exposed to hyperglycemic conditions, $\mathrm{Yu}$ et al. reported a reduced amount of Nav1.5 channels in the membrane. The excessive O-linked GlcNAcylation led to abnormal Nav1.5 aggregation in the cytoplasm and defective trafficking of the channel to the membrane (Yu et al., 2018). Nav1.5 channels open during the depolarization phase and then rapidly inactivate. However, some channels might reopen creating a persistent or late sodium current or $\mathrm{I}_{\mathrm{Na}, \mathrm{L}}$ that interferes with the repolarization (Zaza and Rocchetti, 2013). If the contribution of the late component of the $\mathrm{I}_{\mathrm{Na}}$ increases, $\mathrm{AP}$ duration can prolong excessively increasing the risk of arrhythmia. This might happen in diabetes; in fact, increased $\mathrm{I}_{\mathrm{Na}, \mathrm{L}}$ has been found in type 1 and type $2(\mathrm{db} / \mathrm{db})$ mice with 

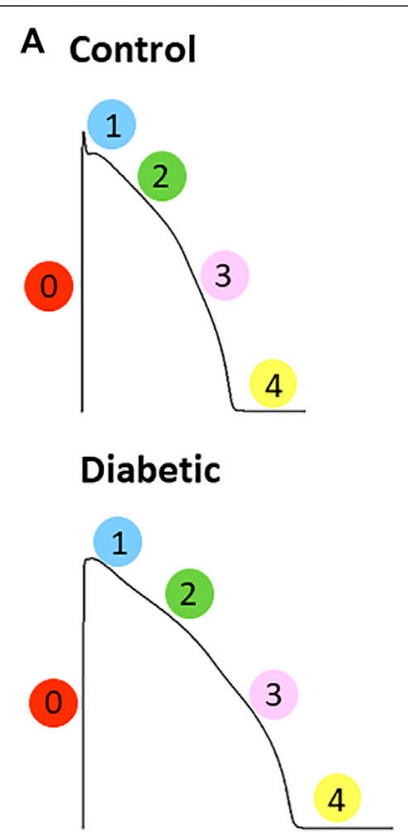

\begin{tabular}{|c|c|c|c|}
\hline $\begin{array}{l}\text { AP } \\
\text { Phase }\end{array}$ & Current & Protein & $\begin{array}{l}\text { Type of } \\
\text { Diabetes }\end{array}$ \\
\hline 0 & $\begin{array}{l}\downarrow I_{\mathrm{Na}} \\
\uparrow \mathrm{I}_{\mathrm{Na}-\mathrm{L}}\end{array}$ & $\downarrow$ Nav1.5 & $T 1 D$ \& $T 2 D$ \\
\hline 1 & $\begin{array}{l}\downarrow \mathrm{I}_{\text {to }} \\
\downarrow \mathrm{I}_{\text {Kur }}\end{array}$ & $\begin{array}{l}\downarrow K v 4.3, \mathrm{Kv4} .2 \\
\downarrow K v 1.5\end{array}$ & $\begin{array}{l}\mathrm{T} 1 \mathrm{D} \& \mathrm{~T} 2 \mathrm{D} \\
\mathrm{T} 1 \mathrm{D} \& \mathrm{~T} 2 \mathrm{D}\end{array}$ \\
\hline 2 & $\downarrow \mathrm{I}_{\mathrm{CaL}}$ & $\downarrow$ Cav1.2 & $T 1 D \& T 2 D$ \\
\hline 3 & $\begin{array}{l}\downarrow \mathrm{I}_{\mathrm{Ks}} \\
\downarrow \mathrm{I}_{\mathrm{Kr}}\end{array}$ & $\begin{array}{l}=\mathrm{Kv} 7.1, \downarrow \operatorname{minK} \\
\downarrow \mathrm{hERG}\end{array}$ & $\begin{array}{l}T 1 D \\
T 1 D \text { \& } T 2 D\end{array}$ \\
\hline 4 & $\begin{array}{l}=I_{\mathrm{K} 1} \\
? \mathrm{I}_{\mathrm{K} 1} \\
? \mathrm{I}_{\mathrm{NCX}}\end{array}$ & $\begin{array}{l}=\operatorname{Kir} 2.1 \\
\downarrow \text { Kir2.1 } \\
\uparrow \text { NCX }\end{array}$ & $\begin{array}{l}\text { T1D } \\
\text { T2D } \\
\text { T2D }\end{array}$ \\
\hline
\end{tabular}

FIGURE 3 | Diabetes affects the depolarizing and repolarizing currents responsible for the cardiac action potential. (A) Action potential depictions of a control and a diabetic heart (numbers indicate the phase of the AP) showing that diabetes changes action potential shape and prolongs its duration. (B) Summary of the alterations in the cardiac ion currents and the respective channel-forming proteins obtained in animal models of TD1 and T2D. See text for references.

prolonged QTc (Lu et al., 2013). Moreover, diabetic mice treated with the $\mathrm{I}_{\mathrm{Na}, \mathrm{L}}$ inhibitor GS967 were more resistant to develop atrial fibrillation under an arrhythmia-inducing protocol than untreated diabetic animals (Jin et al., 2019). In addition, cultured cells incubated in high glucose conditions showed an increase in the late sodium current (Fouda et al., 2020). Different signaling pathways, metabolites and mechanisms regulate the late sodium current (Horváth et al., 2020). In diabetic mice, attenuated insulin/PI3K/Akt signaling increases $\mathrm{I}_{\mathrm{Na}, \mathrm{L}}$, contributing to the subsequent APD and QTc prolongations (Lu et al., 2013).

\section{Calcium Current and Calcium Handling}

The L-type calcium current or $\mathrm{I}_{\mathrm{Ca}-\mathrm{L}}$ is a depolarizing current active during the phase of repolarization of the action potential and is the current responsible for the maintenance of the plateau phase. Regarding the $\mathrm{I}_{\mathrm{Ca}-\mathrm{L}}$, experiments with animal models have yielded confusing results. Some groups found no effects upon the current amplitude and the biophysical behavior of the calcium channel (Jourdon and Feuvray, 1993; Tsuchida et al., 1994; Lengyel et al., 2007; Lengyel et al., 2008) in type 1 diabetic models. On the contrary, other groups described a reduction in the current amplitude and a slowing in the current inactivation kinetics (Horackova and Murphy, 1988; Wang et al., 1995; Chattou et al., 1999). Finally, some groups reported a reduction of $\mathrm{I}_{\mathrm{Ca}-\mathrm{L}}$ but no effect on the channel behavior. In this sense, the reduction in the cardiac $\mathrm{I}_{\mathrm{Ca}-\mathrm{L}}$ density correlated with a decreased expression of its channel-forming protein Cav1.2 in Akita mice, a genetic model of T1D with defective insulin production, as well as in models of T2D like the $d b / d b$ obese mice and Zucker obese rats (Pereira et al., 2006; Lu et al.,
2007; Fu et al., 2019). Electrophysiological recordings of singlechannel activity showed that the biophysical properties of the calcium channel were similar in control and diabetic animals (Pereira et al., 2006).

The reason behind these discrepant results is not clear. It might be related with methodological aspects in current recordings, such as the patch-clamp configuration or the charge carrier used in the experiment $\left(\mathrm{Ca}^{2+}\right.$ or $\left.\mathrm{Ba}^{2+}\right)$. There could also be intrinsic differences in the diabetic models, for instance, induced $v s$. genetic. The experimental conditions for current recordings are also crucial, since the amplitude of the L-type calcium current is very sensitive to the intracellular calcium content. In physiological conditions, L-type calcium channels inactivate via $\mathrm{Ca}^{2+}$-dependent inactivation, mainly by the calcium released from the sarcoplasmic reticulum (Pelzer et al., 1990; Sham, 1997; Kubalová, 2003). Thus, if intracellular $\mathrm{Ca}^{2+}$ is buffered during the current recording, differences in current behavior between control and diabetic cardiomyocytes might not be observed. However, experimental conditions that preserve the intracellular $\mathrm{Ca}^{2+}$ can differentially affect the behavior of the $\mathrm{I}_{\mathrm{Ca}-\mathrm{L}}$ in control and diabetic cells. In fact, intracellular calcium handling is altered in the diabetic myocardium (Allo et al., 1991), showing a characteristic reduced systolic $\mathrm{Ca}^{2+}$ and an augmented diastolic $\mathrm{Ca}^{2+}$.

Diabetes induces changes in several proteins involved in calcium handling, what leads to an increase in the cytosolic $\left(\mathrm{Ca}^{2+}\right)$. Diabetes prolongs the duration of both the contraction and the relaxation phases of the cardiac cycle (Regan et al., 1974; Feuvray et al., 1979; Fein et al., 1980). In the diabetic heart, $\mathrm{Ca}^{2+}$ release from the sarcoplasmic reticulum during systole is 
depressed, mainly due to a downregulation of $\mathrm{Ca}^{2+}$-releasing proteins at the SR membrane. In this sense, mRNA and protein levels of ryanodine receptors (RYRs) are reduced in diabetes and become fully restored after insulin supplementation (Teshima et al., 2000; Netticadan et al., 2001). However, more characteristic of the diabetic myocardium is the diastolic calcium overload, which is increased about three fold (Allo et al., 1991). Diabetes increases the opening probability of RYRs and leads to diastolic $\mathrm{Ca}^{2+}$ leak to the cytoplasm (Singh et al., 2018). In addition, calcium reuptake to the $\mathrm{SR}$ is also compromised because diabetic cardiomyopathy reduces the expression of the sarcoplasmic reticulum $\mathrm{Ca}^{2+}$-ATPase (SERCA2) as well as its apparent affinity for $\mathrm{Ca}^{2+}$ (Teshima et al., 2000; Netticadan et al., 2001), (Zhong et al., 2001; Abe et al., 2002; Razeghi et al., 2002). As a result, diabetic cardiomyocytes have higher diastolic calcium levels caused by a markedly impaired calcium uptake (Penpargkul et al., 1981; Horackova and Murphy, 1988; Fein et al., 1990; Golfman et al., 1996). Thus, diabetic cardiomyocytes have less calcium available for the contraction during systole together with an excess of diastolic calcium that impairs relaxation during diastole.

\section{The Repolarizing Potassium Currents}

Several potassium currents determine the action potential repolarization phase. In the human heart these are the transient outward or $I_{t o}$, the ultrarapid delayed rectifier or $\mathrm{I}_{\mathrm{Kur}}$, the rapid delayed rectifier or $\mathrm{I}_{\mathrm{Kr}}$, the slow delayed rectifier or $\mathrm{I}_{\mathrm{Ks}}$, and the inward rectifier or $\mathrm{I}_{\mathrm{K} 1}$ (Chiamvimonvat et al., 2017). Diabetes does not change the inward rectifier, the current that contributes to the final phase of the repolarization (Magyar et al., 1992; Casis et al., 2000).

On the contrary, $\mathrm{I}_{\mathrm{to}}$, which is the dominant ventricular repolarizing current in rodents, is highly affected by T1D. A reduction in the expression of the channel-forming proteins Kv4.3 and Kv4.2 and the accessory subunit KChIP2 (Qin et al., 2001; Lengyel et al., 2007; Torres-Jacome et al., 2013) caused the reduction in the amplitude of $\mathrm{I}_{\text {to }}$ (Magyar et al., 1992; Shimoni et al., 1994; Xu et al., 1996; Casis et al., 2000). In addition, diabetes accelerated $\mathrm{I}_{\mathrm{to}}$ current inactivation (Magyar et al., 1992; Casis et al., 2000) due to a reduction in the Kv4.3 channel phosphorylation by CaMKII (Gallego et al., 2008). This contributed to the reduction of the total current and the lengthening of the action potential duration. Regarding $\mathrm{I}_{\mathrm{Kur}}$, diabetes reduced the expression of the pore forming protein Kv1.5, thus inhibiting the current (Casis et al., 2000; TorresJacome et al., 2013).

The delayed rectifiers are virtually absent in rodents; therefore, they have been analyzed mostly in type 1 diabetic rabbits and dogs. The amplitude of the slow delayed rectifier $\mathrm{I}_{\mathrm{Ks}}$ was reduced (Lengyel et al., 2007; Lengyel et al., 2008) which correlated with the reduced expression levels of the accessory subunit mink, whereas the pore-forming subunit Kv7.1 was not or little affected (Lengyel et al., 2007; Zhang et al., 2007). Regarding the rapid delayed rectifier, most of the studies reported no effect of diabetes on $\mathrm{I}_{\mathrm{Kr}}$ amplitude and properties (Lengyel et al., 2007; Lengyel et al., 2008; Torres-Jacome et al., 2013). However, experiments made in rabbits with long diabetes duration showed significant reduction of both the $\mathrm{I}_{\mathrm{Kr}}$ amplitude and the expression of its poreforming protein ERG (Zhang et al., 2006; Zhang et al., 2007).

A combination of factors can lead to the reduced electrical activity and expression of cardiac potassium channels. In type 1 diabetic animals, insulin treatment restored some but not all the altered currents (Zhang et al., 2006; Lengyel et al., 2007). The impaired metabolic status of the diabetic cells might also affect protein synthesis. For instance, in vitro activation of the AMPdependent protein kinase reduced several $\mathrm{K}^{+}$repolarizing currents in a similar fashion than diabetes (Torres-Jacome et al., 2013). On the other hand, diabetes induced a sterile inflammation that increased the IL- $1 \mathrm{~b}$ release from cardiac macrophages and led to the reduction of the $I_{\text {to }}$ (Monnerat et al., 2016).

The literature regarding cardiac electrical remodeling in T2D, however, is very limited. A few studies reported a prolongation of APD and a reduction of the amplitude of the ventricular $\mathrm{I}_{\text {to }}$ current in the genetic models $\mathrm{WBN} / \mathrm{Kob}$ rats (Tsuchida et al., 1994; Tsuchida and Watajima, 1997), leptinreceptor deficient homozygous $\mathrm{db} / \mathrm{db}$ mice (Shimoni et al., 2004) or the Otsuka-Long-Evans-Tokushima Fatty rats (Sato et al., 2014). Similarly, $\mathrm{I}_{\text {to }}, \mathrm{I}_{\mathrm{Kur}}$ and $\mathrm{I}_{\mathrm{Ca}-\mathrm{L}}$ currents, as well as their corresponding channel-forming proteins, were reduced in the atria of Zucker diabetic fatty rats (Fu et al., 2019). Regarding humans, a study in elderly type 2 diabetic patients (Ashrafi et al., 2017) showed a reduction of the mRNAs encoding for hERG and Kir channels responsible for $\mathrm{I}_{\mathrm{Kr}}$ and $\mathrm{I}_{\mathrm{K} 1}$, and an increase of the $\mathrm{Na}^{+} / \mathrm{Ca}^{2+}$ exchanger (NCX) expression. Although channel protein levels and current recordings were not assessed and the study was performed in few, aged and poly-medicated patients, this is the first work that directly compares the expression of cardiac channels between diabetic and non-diabetic humans (Hancox, 2017).

\section{SAFETY ASSESSMENT OF ANTIDIABETIC DRUGS}

\section{Proarrhythmic Safety of New Drugs}

Like diabetes, other disorders cause metabolic, endocrine, immune or autonomic disturbances, providing an environment that impairs cardiac ion channel function. Moreover, some drugs can directly inhibit and in some cases activate ion channels, affecting the overall electric response. Therefore, the proarrhythmic propensity of drugs is a matter of concern. Between 1989 and 2003 several drugs were associated with ventricular arrhythmia, mainly torsade de pointes, and were withdrawn from the market [reviewed in Turner et al., 2018]. As a result, in 2005 the International Council for Harmonization (ICH) of Technical Requirements for Pharmaceuticals for Human Use released two guidelines for industry, the nonclinical S7B and the clinical E14, to evaluate potential proarrhythmic effects of new drugs.

Non-clinical testing strategy focused mainly on evaluating the effects of a drug on the hERG channel in vitro, and in electrocardiographic recordings to analyze ventricular repolarization (ICH S7B Guideline, 2005). The hERG channel 
encoded by the human ether-a-go-go-related gene conducts the $\mathrm{I}_{\mathrm{Kr}}$, the main repolarizing current in humans. The blockade of hERG channel is responsible for most of the drug-induced QT prolongations and TdPs because the protein has a peculiar site that effectively accommodates the binding of drugs and makes it particularly susceptible to blockade (Sanguinetti and TristaniFirouzi, 2006). However, not all the hERG-channel blockers prolong the QT interval or induce TdP. Some drugs might have additional effects on other channels that counteract the lengthening of the repolarization, resulting in normal action potential and QT interval duration. Furthermore, QTc prolongation does not necessarily trigger $\mathrm{TdP}$ yet may discontinue compounds from development. Since 2013, the Comprehensive in vitro Proarrhythmia Assay (CiPA) initiative works in a new paradigm for assessment of TdP proarrhythmic risk of new drugs that is not focused exclusively in hERG blockage and QT prolongation (Sager et al., 2014). Instead, the CiPA initiative includes: the in vitro assessment of drug effects on multiple ion channels; the prediction of proarrhythmic risk using in silico models; the in vitro confirmation of proarrhythmicity in human stem cell derived ventricular cardiomyocytes; and electrocardiograms in phase 1 clinical trials (Vicente et al., 2018).

On the other hand, the clinical evaluation of potential proarrhythmic effects consists on the "Thorough QT/QTc" or TQT Study, usually performed before phase 3 clinical development to detect whether the drug has a threshold pharmacologic effect on prolonging repolarization. In the TQT studies, healthy voluntaries receive a negative control (placebo); a positive control (a drug that prolongs the QTc); the drug under development at the maximum recommended therapeutic dose; and the drug at supratherapeutic dose to explore the "worst-case scenario", for instance, in an impaired clearance of the drug. The TQT study is negative if the drug does not prolong the mean QT/ QTc interval more than $5 \mathrm{~ms}$, which is considered the threshold of regulatory concern (ICH E14 Guideline, 2015). However, the TQT study is resource intensive and scientists and regulatory agencies are discussing alternatives that are more effective, such as the intensive assessment of ECG parameters in the first-in-human study (Darpo et al., 2014; ICH E14 Guideline, 2015).

\section{Proarrhythmic Safety of Antidiabetic Drugs}

Since metformin, insulin, sulfonylureas or thiazolidinedione were marketed years before the regulations about arrhythmic safety, TQT studies did not evaluate these classic antidiabetics. On the contrary, newer drugs approved after the ICH E14 guideline, such as semaglutide, have been examined in TQT studies (Demmel et al., 2018). However, evaluation of glucose lowering drugs is very challenging since, for instance, changes in blood glucose concentrations per se may correlate with prolonged QTc (Suys et al., 2006). The Cardiac Safety Research Consortium discussed these major confounding factors (Heller et al., 2015). Variations in glucose, insulin and potassium levels, fasted vs. fed state and the activation of the autonomous nervous system may all affect ventricular repolarization, as well as other ECG parameters like $\mathrm{RR}$ interval duration and the T-wave morphology. This complicates the design and interpretation of TQT studies for assessing antidiabetic compounds.

\section{Glucose-Lowering Treatment for Patients at Cardiovascular Risk}

On the other hand, although the incidence of cardiovascular disease (CVD) has declined in both adults with and without diabetes over the last few decades, diabetic patients still have 2fold greater risk of CVD compared with the non-diabetic population (Fox et al., 2004; Preis et al., 2009). In addition, studies of the agonist of the peroxisome proliferator-activated receptor families alpha and gamma muraglitazar, an agonist of the peroxisome proliferator-activated receptor (PPAR), and the thiazolidinedione rosiglitazone, concluded an increase in the risk of death and in the incidence of major adverse cardiovascular events compared to standard therapy (Nissen et al., 2005; Nissen and Wolski, 2007). These concerning results precipitated that, in 2008, the FDA issued guidance for industry aimed to ensure that new antidiabetic therapies for T2D do not increase the CVD risk. As a result, during pharmacological development of new antidiabetic drugs, Cardiovascular Outcome Trials (CVOTs) must be performed on selected type 2 diabetic patients at higher risk of cardiovascular events (Food and Drug Administration, 2008). Primary outcome in CVOTs is typically a composite of death of cardiovascular cause, nonfatal myocardial infarction and non-fatal stroke. Secondary outcomes may include hospitalization for heart failure, acute coronary syndrome and revascularization (Schnell et al., 2016). Interestingly, diabetes is the only pathology where routine CVOTs in the absence of safety signals are mandatory.

As with the TQTs, CVOTs were not performed for the old antidiabetic drugs. Three groups of new drugs: dipeptidyl peptidase 4 (DPP-4) inhibitors, sodium-glucose cotransporter 2 (SGLT2) inhibitors and glucagon-like peptide 1 (GLP-1) receptor agonists have undertaken CVOTs. Detailed summaries of completed and ongoing studies have been recently published (Cefalu et al., 2018; Schnell et al., 2019; Schnell et al., 2020). Although some differences between drugs exist, CVOTs confirm that the tested drugs fulfill the FDA requirements because they are not associated with an unacceptable increase in cardiovascular risk; therefore, all of them are safe. The GLP1R agonist liraglutide and the SGLT2 inhibitors empagliflozin and, to a lower extent, canagliflozin, have yielded very positive results. Consequently, the American Diabetes Association recommended incorporating these drugs to the standard therapy in T2D patients with established atherosclerotic cardiovascular disease (Davies et al., 2018).

Furthermore, very recent studies have focused on the potential protective effect of SGLT2 inhibitors against developing arrhythmias. In newly diagnosed diabetic patients, SGTL2 inhibitors associates with a reduced risk of new onset arrhythmia (Chen et al., 2020). Similarly, recent meta-analysis examining arrhythmia outcomes, like atrial fibrillation and ventricular tachycardia, found that SGLT2 inhibitors treatment reduces the risk of cardiac arrhythmias in diabetic patients ( $\mathrm{Li}$ et al., 2021). However, in most trials, information regarding preexisting arrhythmia and anti-arrhythmic therapy were not available. More research will be required to determine the best treatment for those arrhythmic patients who develop diabetes. 
Currently, the ADA recommends the use of either an SGLT2 inhibitor or a GLP-1 receptor agonist to reduce cardiovascular risk because this treatment is appropriate for many patients (ADA, 2021). Although both SGLT2i and GLP-1R agonist could be used in patients with atherosclerotic cardiovascular disease, SGLT2 inhibitors are recommended in patients with heart failure or kidney disease (Dardano et al., 2020).

Among the proposed cardioprotective mechanisms are lowering blood pressure, which may lower cardiac afterload; improving cardiac metabolism increasing energy production; reducing inflammation and cytokine release; preventing adverse cardiac remodeling; reducing sympathetic nerve activity; improving renal function; improving mitochondrial dysfunction and improving ionic dyshomeostasis. Thus, the underlying cardioprotective mechanisms of SGLT2 inhibitors and GLP-1 receptor agonists remain unclear and might involve complementary systemic and direct cardiac effects (recently reviewed in Lahnwong et al., 2018; Dardano et al., 2020; Lopaschuk and Verma, 2020).

Regarding ionic dyshomeostasis and arrhythmic risk, $\left(\mathrm{Na}^{+}\right)$ was elevated in the diabetic myocardium, directly increasing the risk of sudden arrhythmic death (Lambert et al., 2015). Empagliflocin inhibits the $\mathrm{Na}^{+} / \mathrm{H}^{+}$exchanger and reduces the sodium and calcium concentration (Baartscheer et al., 2017). Another SGLT2 inhibitor, dapagliflozin, reduced the membrane expression of the $\mathrm{Na}^{+} / \mathrm{H}^{+}$exchanger, the $\mathrm{Na}^{+} / \mathrm{Ca}^{2+}$ exchanger and the L-type calcium channel in $\mathrm{db} / \mathrm{db}$ mice (Arow et al., 2020). The resulting reduction of the cytoplasmic $\left(\mathrm{Na}^{+}\right)$and $\left(\mathrm{Ca}^{2+}\right)$ might reduce the risk of developing potentially lethal arrhythmias. Very interestingly, in insulin resistant rats dapagliflozin-treatment improved cardiac repolarization. Daplagliflozin supressed QT interval and AP prolongation, mainly by restoring the depressed potassium currents $\mathrm{I}_{\text {to }}$ and $\mathrm{I}_{\mathrm{K} 1}$, but also by reducing $\mathrm{I}_{\mathrm{Na}}$ (Durak et al., 2018).

\section{REFERENCES}

Abe, T., Ohga, Y., Tabayashi, N., Kobayashi, S., Sakata, S., Misawa, H., et al. (2002). Left Ventricular Diastolic Dysfunction in Type 2 Diabetes Mellitus Model Rats. Am. J. Physiology-Heart Circulatory Physiol. 282 (1), H138-H148. doi:10.1152/ ajpheart.2002.282.1.h138

ADA (2021). Cardiovascular Disease and Risk Management: Standards of Medical Care in Diabetes-2021. Diabetes Care 44, S125-S150.

Al-awar, A., Kupai, K., Veszelka, M., Szücs, G., Attieh, Z., Murlasits, Z., et al. (2016). Experimental Diabetes Mellitus in Different Animal Models. J. Diabetes Res. 2016, 9051426. doi:10.1155/2016/9051426

Allo, S. N., Lincoln, T. M., Wilson, G. L., Green, F. J., Watanabe, A. M., and Schaffer, S. W. (1991). Non-Insulin-Dependent Diabetes-Induced Defects in Cardiac Cellular Calcium Regulation. Am. J. Physiology-Cell Physiol. 260 (6), C1165-C1171. doi:10.1152/ajpcell.1991.260.6.c1165

Arow, M., Waldman, M., Yadin, D., Nudelman, V., Shainberg, A., Abraham, N. G., et al. (2020). Sodium-glucose Cotransporter 2 Inhibitor Dapagliflozin Attenuates Diabetic Cardiomyopathy. Cardiovasc. Diabetology 19 (1), 7. doi:10.1186/s12933-019-0980-4

Ashrafi, R., Modi, P., Oo, A. Y., Pullan, D. M., Jian, K., Zhang, H., et al. (2017). Arrhythmogenic Gene Remodelling in Elderly Patients with Type 2 Diabetes with Aortic Stenosis and normal Left Ventricular Ejection Fraction. Exp. Physiol. 102 (11), 1424-1434. doi:10.1113/ep086412

\section{CONCLUSION AND FUTURE PRESPECTIVES}

Both T1D and T2D induce a cardiac remodeling that leads to mechanical dysfunction and/or cardiac arrhythmias. Experiments with animal models have consistently shown that diabetes alters the expression and regulation of cardiac ion channels and transporters, which impairs impulse generation, conduction, excitation-contraction coupling and myocyte contractility.

Prolonged QTc interval duration persists in a number of treated diabetic patients, indicating that strict glycemic control is not sufficient to normalize the electrophysiological disturbances. Available glucoselowering drugs that improve cardiovascular prognosis are crucial in the management of type 2 diabetic patients with established cardiovascular disease or at high cardiovascular risk. Further studies are needed to elucidate if cardioprotection includes electrical remodeling and prolonged repolarization. This could be of particular interest for patients with diabetes-associated complications that may increase the risk of arrhythmia.

\section{AUTHOR CONTRIBUTIONS}

MG and OC conceptualization of the manuscript. MG, OC, JZ, $\mathrm{BA}$ and $\mathrm{AA}$ writing the original draft. $\mathrm{MG}, \mathrm{OC}$, and $\mathrm{BA}$ : writing review and editing. All authors contributed to the article and approved the submitted version.

\section{FUNDING}

This work was supported by grants from the Basque Government: Govierno Vasco PIBA2018-58, GIC18/150 and IT1196-19. AA received a predoctoral fellowship from the Basque Government.

Baartscheer, A., Schumacher, C. A., Wüst, R. C. I., Fiolet, J. W. T., Stienen, G. J. M., Coronel, R., et al. (2017). Empagliflozin Decreases Myocardial Cytoplasmic $\mathrm{Na}+$ through Inhibition of the Cardiac $\mathrm{Na}+\mathrm{H}+$ Exchanger in Rats and Rabbits. Diabetologia 60 (3), 568-573. doi:10.1007/s00125-016-4134-x

Battiprolu, P. K., Lopez-Crisosto, C., Wang, Z. V., Nemchenko, A., Lavandero, S., and Hill, J. A. (2013). Diabetic Cardiomyopathy and Metabolic Remodeling of the Heart. Life Sci. 92 (11), 609-615. doi:10.1016/ j.lfs.2012.10.011

Bellavere, F., Ferri, M., Guarini, L., Bax, G., Piccoli, A., Cardone, C., et al. (1988). Prolonged QT Period in Diabetic Autonomic Neuropathy: a Possible Role in Sudden Cardiac Death? Heart 59 (3), 379-383. doi:10.1136/hrt.59.3.379

Brown, D. W., Giles, W. H., Greenlund, K. J., Valdez, R., and Croft, J. B. (2001). Impaired Fasting Glucose, Diabetes Mellitus, and Cardiovascular Disease Risk Factors Are Associated with Prolonged QTc Duration. Results from the Third National Health and Nutrition Examination Survey. Eur. J. Cardiovasc. Prev. Rehabil. 8 (4), 227-233. doi:10.1177/174182670100800407

Bugger, H., and Abel, E. D. (2014). Molecular Mechanisms of Diabetic Cardiomyopathy. Diabetologia 57 (4), 660-671. doi:10.1007/s00125-0143171-6

Cardoso, C., Salles, G., Bloch, K., Deccache, W., and Siqueira, A. G. (2001). Clinical Determinants of Increased QT Dispersion in Patients with Diabetes Mellitus. Int. J. Cardiol. 79 (2-3), 253-262. doi:10.1016/s0167-5273(01)00443-0

Casis, O., and Echevarria, E. (2004). Diabetic Cardiomyopathy: Electromechanical Cellular Alterations. Cvp 2 (3), 237-248. doi:10.2174/1570161043385655 
Casis, O., Gallego, M., Iriarte, M., and Sánchez-Chapula, J. A. (2000). Effects of Diabetic Cardiomyopathy on Regional Electrophysiologic Characteristics of Rat Ventricle. Diabetologia 43 (1), 101-109. doi:10.1007/s001250050013

Cefalu, W. T., Kaul, S., Gerstein, H. C., Holman, R. R., Zinman, B., Skyler, J. S., et al. (2018). Cardiovascular Outcomes Trials in Type 2 Diabetes: Where Do We Go from Here? Reflections from aDiabetes CareEditors' Expert Forum. Dia Care 41 (1), 14-31. doi:10.2337/dci17-0057

Chambers, J. B., Sampson, M. J., Sprigings, D. C., and Jackson, G. (1990). Qt Prolongation on the Electrocardiogram in Diabetic Autonomic Neuropathy. Diabetic Med. 7 (2), 105-110. doi:10.1111/j.1464-5491.1990.tb01342.x

Chattou, S., Diacono, J., and Feuvray, D. (1999). Decrease in Sodium-Calcium Exchange and Calcium Currents in Diabetic Rat Ventricular Myocytes. Acta Physiol. Scand. 166 (2), 137-144. doi:10.1046/j.1365-201x.1999.00547.x

Chen, C., Wang, W., Zhou, W., Jin, J., Chen, W., Zhu, D., et al. (2019). Nocturnal Ventricular Arrhythmias Are Associated with the Severity of Cardiovascular Autonomic Neuropathy in Type 2 Diabetes. J. Diabetes 11 (10), 794-801. doi:10.1111/1753-0407.12908

Chen, H.-Y., Huang, J.-Y., Siao, W.-Z., and Jong, G.-P. (2020). The Association between SGLT2 Inhibitors and New-Onset Arrhythmias: a Nationwide Population-Based Longitudinal Cohort Study. Cardiovasc. Diabetology 19 (1), 73. doi:10.1186/s12933-020-01048-x

Chiamvimonvat, N., Chen-Izu, Y., Clancy, C. E., Deschenes, I., Dobrev, D., Heijman, J., et al. (2017). Potassium Currents in the Heart: Functional Roles in Repolarization, Arrhythmia and Therapeutics. J. Physiol. 595 (7), 2229-2252. doi:10.1113/jp272883

Cox, A. J., Azeem, A., Yeboah, J., Soliman, E. Z., Aggarwal, S. R., Bertoni, A. G., et al. (2014). Heart Rate-Corrected QT Interval Is an Independent Predictor of All-Cause and Cardiovascular Mortality in Individuals with Type 2 Diabetes: The Diabetes Heart Study. Dia Care 37 (5), 1454-1461. doi:10.2337/dc13-1257

Dardano, A., Miccoli, R., Bianchi, C., Daniele, G., and Del Prato, S. (2020). Invited Review. Series: Implications of the Recent CVOTs in Type 2 Diabetes. Diabetes Res. Clin. Pract. 162, 108112. doi:10.1016/j.diabres.2020.108112

Darpo, B., Garnett, C., Benson, C. T., Keirns, J., Leishman, D., Malik, M., et al. (2014). Cardiac Safety Research Consortium: Can the Thorough QT/QTc Study Be Replaced by Early QT Assessment in Routine Clinical Pharmacology Studies? Scientific Update and a Research Proposal for a Path Forward. Am. Heart J. 168 (3), 262-272. doi:10.1016/j.ahj.2014.06.003

Davies, M. J., D’Alessio, D. A., Fradkin, J., Kernan, W. N., Mathieu, C., Mingrone, G., et al. (2018). Management of Hyperglycemia in Type 2 Diabetes, 2018. A Consensus Report by the American Diabetes Association (ADA) and the European Association for the Study of Diabetes (EASD)A Consensus Report by the American Diabetes Association (ADA) and the European Association for the Study of Diabetes (EASD). Dia Care 41 (12), 2669-2701. doi:10.2337/dci18-00332018

Demmel, V., Sandberg-Schaal, A., Jacobsen, J. B., Golor, G., Pettersson, J., and Flint, A. (2018). No QTc Prolongation with Semaglutide: A Thorough QT Study in Healthy Subjects. Diabetes Ther. 9 (4), 1441-1456. doi:10.1007/s13300-018-0442-0

Devereux, R. B., Roman, M. J., Paranicas, M., O'Grady, M. J., Lee, E. T., Welty, T. K., et al. (2000). Impact of Diabetes on Cardiac Structure and Function. Circulation 101 (19), 2271-2276. doi:10.1161/01.cir.101.19.2271

Duckworth, W., Abraira, C., Moritz, T., Reda, D., Emanuele, N., Reaven, P. D., et al. (2009). Glucose Control and Vascular Complications in Veterans with Type 2 Diabetes. N. Engl. J. Med. 360 (2), 129-139. doi:10.1056/nejmoa0808431

Durak, A., Olgar, Y., Degirmenci, S., Akkus, E., Tuncay, E., and Turan, B. (2018). A SGLT2 Inhibitor Dapagliflozin Suppresses Prolonged VentricularRepolarization through Augmentation of Mitochondrial Function in Insulin-Resistant Metabolic Syndrome Rats. Cardiovasc. Diabetology 17, 144. doi:10.1186/s12933-018-0790-0

Ewing, D. J., Boland, O., Neilson, J. M. M., Cho, C. G., and Clarke, B. F. (1991). Autonomic Neuropathy, QT Interval Lengthening, and Unexpected Deaths in Male Diabetic Patients. Diabetologia 34 (3), 182-185. doi:10.1007/ bf00418273

Fein, F., Aronson, R. S., Nordin, C., Miller-Green, B., and Sonnenblick, E. H. (1983). Altered Myocardial Response to Ouabain in Diabetic Rats: Mechanics and Electrophysiology. J. Mol. Cell Cardiol. 15 (11), 769-784. doi:10.1016/00222828(83)90336-x

Fein, F. S., Kornstein, L. B., Strobeck, J. E., Capasso, J. M., and Sonnenblick, E. H. (1980). Altered Myocardial Mechanics in Diabetic Rats. Circ. Res. 47 (6), 922-933. doi:10.1161/01.res.47.6.922
Fein, F. S., Zola, B. E., Malhotra, A., Cho, S., Factor, S. M., Scheuer, J., et al. (1990). Hypertensive-Diabetic Cardiomyopathy in Rats. Am. J. Physiology-Heart Circulatory Physiol. 258 (3), H793-H805. doi:10.1152/ajpheart.1990.258.3.h793

Ferrannini, E., and DeFronzo, R. A. (2015). Impact of Glucose-Lowering Drugs on Cardiovascular Disease in Type 2 Diabetes. Eur. Heart J. 36 (34), 2288-2296. doi:10.1093/eurheartj/ehv239

Feuvray, D., Idell-Wenger, J. A., and Neely, J. R. (1979). Effects of Ischemia on Rat Myocardial Function and Metabolism in Diabetes. Circ. Res. 44 (3), 322-329. doi:10.1161/01.res.44.3.322

Food and Drug Administration, (2008). Guidance for Industry Diabetes Mellitus - Evaluating Cardiovascular Risk in New Antidiabetic Therapies to Treat Type 2 Diabetes. Food and Drug Administration.

Fouda, M. A., Ghovanloo, M. R., and Ruben, P. C. (2020). Cannabidiol Protects against High Glucose-Induced Oxidative Stress and Cytotoxicity in Cardiac Voltage-Gated Sodium Channels. Br. J. Pharmacol.

Fowlkes, V., Clark, J., Fix, C., Law, B. A., Morales, M. O., Qiao, X., et al. (2013). Type II Diabetes Promotes a Myofibroblast Phenotype in Cardiac Fibroblasts. Life Sci. 92 (11), 669-676. doi:10.1016/j.lfs.2013.01.003

Fox, C. S., Coady, S., Sorlie, P. D., Levy, D., Meigs, J. B., D’Agostino, R. B., et al. (2004). Trends in Cardiovascular Complications of Diabetes. Jama 292 (20), 2495-2499. doi:10.1001/jama.292.20.2495

Fu, L., Rao, F., Lian, F., Yang, H., Kuang, S., Wu, S., et al. (2019). Mechanism of Electrical Remodeling of Atrial Myocytes and its Influence on Susceptibility to Atrial Fibrillation in Diabetic Rats. Life Sci. 239, 116903. doi:10.1016/ j.lfs. 2019.116903

Gallego, M., and Casis, O. (2014). Cellular Mechanism Underlying the Misfunction of Cardiac Ionic Channels in Diabetes, 233. NEW YORK: Springer, 199.

Gallego, M., Fernandez, D., Ahyayauch, H., Casis, E., and Casis, O. (2008). Reduced Calmodulin Expression Accelerates Transient Outward Potassium Current Inactivation in Diabetic Rat Heart. Cell Physiol. Biochem. 22 (5-6), 625-634. doi:10.1159/000185546

Goldfine, A. B. (2008). Assessing the Cardiovascular Safety of Diabetes Therapies. N. Engl. J. Med. 359 (11), 1092-1095. doi:10.1056/nejmp0805758

Golfman, L. S., Takeda, N., and Dhalla, N. S. (1996). Cardiac Membrane Ca(2+)Transport in Alloxan-Induced Diabetes in Rats. Diabetes Res. Clin. Pract. 31 (Suppl. 1), 73. doi:10.1016/0168-8227(96)01233-8

Goudis, C. A., Korantzopoulos, P., Ntalas, I. V., Kallergis, E. M., Liu, T., and Ketikoglou, D. G. (2015). Diabetes Mellitus and Atrial Fibrillation: Pathophysiological Mechanisms and Potential Upstream Therapies. Int. J. Cardiol. 184, 617-622. doi:10.1016/j.ijcard.2015.03.052

Grisanti, L. A. (2018). Diabetes and Arrhythmias: Pathophysiology, Mechanisms and Therapeutic Outcomes. Front. Physiol. 9, 1669. doi:10.3389/fphys.2018.01669

Group, T. A. C. (2008). Intensive Blood Glucose Control and Vascular Outcomes in Patients with Type 2 Diabetes. New Engl. J. Med. 358 (24), 2560-2572.

Hancox, J. C. (2017). A Basis for Human QT Interval Prolongation and Arrhythmia Risk in Type 2 Diabetes? Exp. Physiol. 102 (11), 1395-1396. doi:10.1113/ep086618

Hegyi, B., Bers, D. M., and Bossuyt, J. (2019). CaMKII Signaling in Heart Diseases: Emerging Role in Diabetic Cardiomyopathy. J. Mol. Cell Cardiol. 127, 246-259. doi:10.1016/j.yjmcc.2019.01.001

Heller, S., Darpö, B., Mitchell, M. I., Linnebjerg, H., Leishman, D. J., Mehrotra, N., et al. (2015). Considerations for Assessing the Potential Effects of Antidiabetes Drugs on Cardiac Ventricular Repolarization: A Report from the Cardiac Safety Research Consortium. Am. Heart J. 170 (1), 23-35. doi:10.1016/ j.ahj.2015.03.007

Horackova, M., and Murphy, M. G. (1988). Effects of Chronic Diabetes Mellitus on the Electrical and Contractile activities,45Ca2+ Transport, Fatty Acid Profiles and Ultrastructure of Isolated Rat Ventricular Myocytes. Pflugers Arch. 411 (5), 564-572. doi:10.1007/bf00582379

Horváth, B., Hézső, T., Kiss, D., Kistamás, K., Magyar, J., Nánási, P. P., et al. (2020). Late Sodium Current Inhibitors as Potential Antiarrhythmic Agents. Front. Pharmacol. 11 (413). doi:10.3389/fphar.2020.00413

Howarth, F. C., Qureshi, M. A., Jayaprakash, P., Parekh, K., Oz, M., Dobrzynski, H., et al. (2018). The Pattern of mRNA Expression Is Changed in Sinoatrial Node from Goto-Kakizaki Type 2 Diabetic Rat Heart. J. Diabetes Res. 2018, 8454078. doi:10.1155/2018/8454078

Howarth, F. C., Nowotny, N., Zilahi, E., El Haj, M. A., and Lei, M. (2007). Altered Expression of gap junction Connexin Proteins May Partly Underlie Heart 
Rhythm Disturbances in the Streptozotocin-Induced Diabetic Rat Heart. Mol. Cell. Biochem. 305 (1-2), 145-151. doi:10.1007/s11010-007-9537-z

Huxley, R. R., Alonso, A., Lopez, F. L., Filion, K. B., Agarwal, S. K., Loehr, L. R., et al. (2012). Type 2 Diabetes, Glucose Homeostasis and Incident Atrial Fibrillation: the Atherosclerosis Risk in Communities Study. Heart 98 (2), 133-138. doi:10.1136/heartjnl-2011-300503

ICH E14 Guideline, (2015). The clinical evaluation of QT/QTc interval prolongation and proarrhythmic potential for non-antiarrhythmic drugs. International Conference on Harmonization of Technical Requirements for Registration of Pharmaceuticals for Human Use.

ICH S7B Guideline, (2005). The non-clinical evaluation of the potential for delayed ventricular repolarization ( $Q T$ interval prolongation) by human pharmaceuticals. International Conference on Harmonization of Technical Requirements for Registration of Pharmaceuticals for Human Use.

Ionut, V., Liu, H., Mooradian, V., Castro, A. V. B., Kabir, M., Stefanovski, D., et al. (2010). Novel Canine Models of Obese Prediabetes and Mild Type 2 Diabetes. Am. J. Physiology-Endocrinology Metab. 298 (1), E38-E48. doi:10.1152/ ajpendo.00466.2009

Jermendy, G. (2003). Clinical Consequences of Cardiovascular Autonomic Neuropathy in Diabetic Patients. Acta Diabetol. 40, S370-S374. doi:10.1007/ s00592-003-0122-y

Jermendy, G., Koltai, M. Z., and Pogátsa, G. (1990). QT Interval Prolongation in Type 2 (Non-insulin-dependent) Diabetic Patients with Cardiac Autonomic Neuropathy. Acta Diabet. Lat 27 (4), 295-301. doi:10.1007/bf02580933

Jia, G., Hill, M. A., and Sowers, J. R. (2018). Diabetic Cardiomyopathy. Circ. Res. 122 (4), 624-638. doi:10.1161/circresaha.117.311586

Jin, X., Jiang, Y., Xue, G., Yuan, Y., Zhu, H., Zhan, L., et al. (2019). Increase of Late Sodium Current Contributes to Enhanced Susceptibility to Atrial Fibrillation in Diabetic Mice. Eur. J. Pharmacol. 857. doi:10.1016/ j.ejphar.2019.172444

Jourdon, P., and Feuvray, D. (1993). Calcium and Potassium Currents in Ventricular Myocytes Isolated from Diabetic Rats. J. Physiology-London 470, 411-429. doi:10.1113/jphysiol.1993.sp019866

Kannel, W. B., Hjortland, M., and Castelli, W. P. (1974). Role of Diabetes in Congestive Heart Failure: The Framingham Study. Am. J. Cardiol. 34 (1), 29-34. doi:10.1016/0002-9149(74)90089-7

Karam, B. S., Chavez-Moreno, A., Koh, W., Akar, J. G., and Akar, F. G. (2017). Oxidative Stress and Inflammation as central Mediators of Atrial Fibrillation in Obesity and Diabetes. Cardiovasc. Diabetology 16, 120. doi:10.1186/s12933017-0604-9

King, A., and Bowe, J. (2016). Animal Models for Diabetes: Understanding the Pathogenesis and Finding New Treatments. Biochem. Pharmacol. 99, 1-10. doi:10.1016/j.bcp.2015.08.108

King, A. J. (2012). The Use of Animal Models in Diabetes Research. Br. J. Pharmacol. 166 (3), 877-894. doi:10.1111/j.1476-5381.2012.01911.x

Kubalová, Z. (2003). Inactivation of L-type Calcium Channels in Cardiomyocytes. Experimental and Theoretical Approaches. Gen. Physiol. Biophys. 22 (4), 441-454.

Kumar, R., Fisher, M., Whitaker, R., and MacFarlane, P. W. (2004). Effect of Controlling Hyperglycemia with Diet on QT Abnormalities in Newly Diagnosed Patients with Type 2 Diabetes. Diabetes care 27 (11), 2767-2768. doi:10.2337/diacare.27.11.2767-a

Lahnwong, S., Chattipakorn, S. C., and Chattipakorn, N. (2018). Potential Mechanisms Responsible for Cardioprotective Effects of Sodium-Glucose Co-transporter 2 Inhibitors. Cardiovasc. Diabetology 17 (1), 101. doi:10.1186/s12933-018-0745-5

Lambert, R., Srodulski, S., Peng, X., Margulies, K. B., Despa, F., and Despa, S. (2015). Intracellular $\mathrm{Na}+$ Concentration $([\mathrm{Na}+](\mathrm{i}))$ Is Elevated in Diabetic Hearts Due to Enhanced Na+-Glucose Cotransport. J. Am. Heart Assoc. 4 (9), e002183. doi:10.1161/jaha.115.002183

Lee, M., Gardin, J. M., Lynch, J. C., Smith, V.-E., Tracy, R. P., Savage, P. J., et al. (1997). Diabetes Mellitus and Echocardiographic Left Ventricular Function in Free-Living Elderly Men and Women: The Cardiovascular Health Study. Am. Heart J. 133 (1), 36-43. doi:10.1016/s0002-8703(97)70245-x

Lengyel, C., Virag, L., Biro, T., Jost, N., Magyar, J., Biliczki, P., et al. (2007). Diabetes Mellitus Attenuates the Repolarization reserve in Mammalian Heart. Cardiovasc. Res. 73 (3), 512-520. doi:10.1016/j.cardiores.2006.11.010
Lengyel, C., Virág, L., Kovács, P. P., Kristóf, A., Pacher, P., Kocsis, E., et al. (2008). Role of Slow Delayed Rectifier K+-current in QT Prolongation in the AlloxanInduced Diabetic Rabbit Heart. Acta Physiol. 192 (3), 359-368. doi:10.1111/ j.1748-1716.2007.01753.x

Lenzen, S. (2008). The Mechanisms of Alloxan- and Streptozotocin-Induced Diabetes. Diabetologia 51 (2), 216-226. doi:10.1007/s00125-007-0886-7

Li, C.-j., Lv, L., Li, H., and Yu, D.-m. (2012). Cardiac Fibrosis and Dysfunction in Experimental Diabetic Cardiomyopathy Are Ameliorated by Alpha-Lipoic Acid. Cardiovasc. Diabetol. 11, 73. doi:10.1186/1475-2840-11-73

Li, H.-L., Lip, G.-Y. H., Feng, Q., Fei, Y., Tse, Y.-K., Wu, M.-z., et al. (2021). Sodium-glucose Cotransporter 2 Inhibitors (SGLT2i) and Cardiac Arrhythmias: a Systematic Review and Meta-Analysis. Cardiovasc. Diabetology 20 (1), 100. doi:10.1186/s12933-021-01293-8

Li, X., Ren, H., Xu, Z. R., Liu, Y. J., Yang, X. P., and Liu, J. Q. (2012). Prevalence and Risk Factors of Prolonged QTc Interval Among Chinese Patients with Type 2 Diabetes. Exp. Diabetes Res. 2012, 234084. doi:10.1155/2012/234084

Lopaschuk, G. D., and Verma, S. (2020). Mechanisms of Cardiovascular Benefits of Sodium Glucose Co-transporter 2 (SGLT2) Inhibitors. JACC: Basic Translational Sci. 5 (6), 632-644. doi:10.1016/j.jacbts.2020.02.004

Lu, Z., Jiang, Y.-P., Wu, C.-Y. C., Ballou, L. M., Liu, S., Carpenter, E. S., et al. (2013). Increased Persistent Sodium Current Due to Decreased PI3K Signaling Contributes to QT Prolongation in the Diabetic Heart. Diabetes 62 (12), 4257-4265. doi:10.2337/db13-0420

Lu, Z., Jiang, Y.-P., Xu, X.-H., Ballou, L. M., Cohen, I. S., and Lin, R. Z. (2007). Decreased L-type Ca2+ Current in Cardiac Myocytes of Type 1 Diabetic Akita Mice Due to Reduced Phosphatidylinositol 3-kinase Signaling. Diabetes 56 (11), 2780-2789. doi:10.2337/db06-1629

Lu, Z., Lense, L., Sharma, M., Shah, A., Luu, Y., Cardinal, L., et al. (2017). Prevalence of QT Prolongation and Associated LVEF Changes in Diabetic Patients over a Four-Year Retrospective Time Period. J. Community Hosp. Intern. Med. Perspect. 7 (2), 87-94. doi:10.1080/20009666.2017.1320203

Magyar, J., Rusznak, Z., Szentesi, P., Szucs, G., and Kovacs, L. (1992). Action Potentials and Potassium Currents in Rat Ventricular Muscle during Experimental Diabetes. J. Mol. Cell Cardiol. 24 (8), 841-853. doi:10.1016/ 0022-2828(92)91098-p

Masiello, P. (2006). Animal Models of Type 2 Diabetes with Reduced Pancreatic Beta-Cell Mass. Int. J. Biochem. Cel Biol. 38 (5-6), 873-893. doi:10.1016/ j.biocel.2005.09.007

Miragoli, M., Gaudesius, G., and Rohr, S. (2006). Electrotonic Modulation of Cardiac Impulse Conduction by Myofibroblasts. Circ. Res. 98 (6), 801-810. doi:10.1161/01.res.0000214537.44195.a3

Monnerat, G., Alarcon, M. L., Vasconcellos, L. R., Hochman-Mendez, C., Brasil, G., Bassani, R. A., et al. (2016). Macrophage-dependent IL-1 Beta Production Induces Cardiac Arrhythmias in Diabetic Mice. Nat. Commun. 7, 13344. doi:10.1038/ncomms 13344

Naas, A. A. O., Davidson, N. C., Thompson, C., Cummings, F., Ogston, S. A., Jung, R. T., et al. (1998). QT and QTc Dispersion Are Accurate Predictors of Cardiac Death in Newly Diagnosed Non-insulin Dependent Diabetes: Cohort Study. Bmj 316 (7133), 745-746. doi:10.1136/bmj.316.7133.745

Netticadan, T., Temsah, R. M., Kent, A., Elimban, V., and Dhalla, N. S. (2001). Depressed Levels of Ca2+-Cycling Proteins May Underlie Sarcoplasmic Reticulum Dysfunction in the Diabetic Heart. Diabetes 50 (9), 2133-2138. doi:10.2337/diabetes.50.9.2133

Ninkovic, V. M., Ninkovic, S. M., Miloradovic, V., Stanojevic, D., Babic, M., Giga, V., et al. (2016). Prevalence and Risk Factors for Prolonged QT Interval and QT Dispersion in Patients with Type 2 Diabetes. Acta Diabetol. 53 (5), 737-744. doi:10.1007/s00592-016-0864-y

Nissen, S. E., and Wolski, K. (2007). Effect of Rosiglitazone on the Risk of Myocardial Infarction and Death from Cardiovascular Causes. N. Engl. J. Med. 356 (24), 2457-2471. doi:10.1056/nejmoa072761

Nissen, S. E., Wolski, K., and Topol, E. J. (2005). Effect of Muraglitazar on Death and Major Adverse Cardiovascular Events in Patients with Type 2 Diabetes Mellitus. Jama 294 (20), 2581-2586. doi:10.1001/jama.294.20.joc50147

Nygren, A., Olson, M. L., Chen, K. Y., Emmett, T., Kargacin, G., and Shimoni, Y. (2007). Propagation of the Cardiac Impulse in the Diabetic Rat Heart: Reduced Conduction reserve. J. Physiology-London 580 (2), 543-560. doi:10.1113/ jphysiol.2006.123729 
Onay-Besikci, A. (2014). Substrate Metabolism in the Diabetic Heart, 233. NEW YORK: Springer, 76.

Palomer, X., Pizarro-Delgado, J., and Vázquez-Carrera, M. (2018). Emerging Actors in Diabetic Cardiomyopathy: Heartbreaker Biomarkers or Therapeutic Targets? Trends Pharmacological Sciences 39 (5), 452-467. doi:10.1016/j.tips.2018.02.010

Pelzer, D., Pelzer, S., and McDonald, T. F. (1990). Properties and Regulation of Calcium Channels in Muscle Cells. Rev. Physiol. Biochem. Pharmacol. 114, 107-207. doi:10.1007/bfb0031019

Penpargkul, S., Fein, F., Sonnenblick, E. H., and Scheuer, J. (1981). Depressed Cardiac Sarcoplasmic Reticular Function from Diabetic Rats. J. Mol. Cell Cardiol. 13 (3), 303-309. doi:10.1016/0022-2828(81)90318-7

Pereira, L., Matthes, J., Schuster, I., Valdivia, H. H., Herzig, S., Richard, S., et al. (2006). Mechanisms of [Ca2+]i Transient Decrease in Cardiomyopathy of $\mathrm{Db} /$ db Type 2 Diabetic Mice. Diabetes 55 (3), 608-615. doi:10.2337/ diabetes.55.03.06.db05-1284

Podell, B. K., Ackart, D. F., Richardson, M. A., DiLisio, J. E., Pulford, B., and Basaraba, R. J. (2017). A Model of Type 2 Diabetes in the guinea Pig Using Sequential Diet-Induced Glucose Intolerance and Streptozotocin Treatment. Dis. Models Mech. 10 (2), 151-162.

Preis, S. R., Pencina, M. J., Hwang, S.-J., D’Agostino, R. B., Savage., Levy, D., et al. (2009). Trends in Cardiovascular Disease Risk Factors in Individuals with and without Diabetes Mellitus in the Framingham Heart Study. Circulation 120 (3), 212-220. doi:10.1161/circulationaha.108.846519

Qin, D., Huang, B., Deng, L., El-Adawi, H., Ganguly, K., Sowers, J. R., et al. (2001). Downregulation of $\mathrm{K}+$ Channel Genes Expression in Type I Diabetic Cardiomyopathy. Biochem. biophysical Res. Commun. 283 (3), 549-553. doi:10.1006/bbrc.2001.4825

Quagliariello, V., De Laurentiis, M., Cocco, S., Rea, G., Bonelli, A., Caronna, A., et al. (2020). NLRP3 as Putative Marker of Ipilimumab-Induced Cardiotoxicity in the Presence of Hyperglycemia in Estrogen-Responsive and Triple-Negative Breast Cancer Cells. Int. J. Mol. Sci. 21 (20).

Rahnema, P., Shimoni, Y., and Nygren, A. (2011). Reduced Conduction reserve in the Diabetic Rat Heart: Role of iPLA2 Activation in the Response to Ischemia. Am. J. Physiology-Heart Circulatory Physiol. 300 (1), H326-H334. doi:10.1152/ ajpheart.00743.2010

Rautio, E., Gadler, F., Gudbjörnsdottir, S., Franzén, S., Rydén, L., Svensson, A.-M., et al. (2020). Patients with Type 2 Diabetes Have an Increased Demand for Pacemaker Treatment: A Comparison with Age- and Sex-Matched Control Subjects from the General Population. Dia Care 43 (11), 2853-2858. doi:10.2337/dc20-0084

Razeghi, P., Young, M. E., Cockrill, T. C., Frazier, O. H., and Taegtmeyer, H. (2002). Downregulation of Myocardial Myocyte Enhancer Factor 2C and Myocyte Enhancer Factor 2C-Regulated Gene Expression in Diabetic Patients with Nonischemic Heart Failure. Circulation 106 (4), 407-411. doi:10.1161/01.cir.0000026392.80723.dc

Regan, T. J., Ettinger, P. O., Khan, M. I., Jesrani, M. U., Lyons, M. M., Oldewurtel, H. A., et al. (1974). Altered Myocardial Function and Metabolism in Chronic Diabetes Mellitus without Ischemia in Dogs. Circ. Res. 35 (2), 222-237. doi:10.1161/01.res.35.2.222

Rubler, S., Dlugash, J., Yuceoglu, Y. Z., Kumral, T., Branwood, A. W., and Grishman, A. (1972). New Type of Cardiomyopathy Associated with Diabetic Glomerulosclerosis. Am. J. Cardiol. 30 (6), 595-602. doi:10.1016/ 0002-9149(72)90595-4

Sager, P. T., Gintant, G., Turner, J. R., Pettit, S., and Stockbridge, N. (2014). Rechanneling the Cardiac Proarrhythmia Safety Paradigm: A Meeting Report from the Cardiac Safety Research Consortium. Am. Heart J. 167 (3), 292-300. doi:10.1016/j.ahj.2013.11.004

Sanguinetti, M. C., and Tristani-Firouzi, M. (2006). hERG Potassium Channels and Cardiac Arrhythmia. Nature 440 (7083), 463-469. doi:10.1038/nature04710

Sato, T., Kobayashi, T., Kuno, A., Miki, T., Tanno, M., Kouzu, H., et al. (2014). Type 2 Diabetes Induces Subendocardium-Predominant Reduction in Transient Outward K+ Current with Downregulation of Kv4.2 and KChIP2. Am. J. Physiology-Heart Circulatory Physiol. 306 (7), H1054-H1065. doi:10.1152/ ajpheart.00414.2013

Scheen, A. J. (2020). Series: Implications of the Recent CVOTs in Type 2 Diabetes. Diabetes Res. Clin. Pract. 159, 107726. doi:10.1016/j.diabres.2019.05.005
Schnell, O., Standl, E., Catrinoiu, D., Genovese, S., Lalic, N., Skra, J., et al. (2016). Report from the 1st Cardiovascular Outcome Trial (CVOT) Summit of the Diabetes \& Cardiovascular Disease (D\&CVD) EASD Study Group. Cardiovasc. Diabetology 15, 33. doi:10.1186/s12933-016-0357-x

Schnell, O., Standl, E., Catrinoiu, D., Itzhak, B., Lalic, N., Rahelic, D., et al. (2019). Report from the 4th Cardiovascular Outcome Trial (CVOT) Summit of the Diabetes \& Cardiovascular Disease (D\&CVD) EASD Study Group. Cardiovasc. Diabetology 18 (1), 30. doi:10.1186/s12933-019-0822-4

Schnell, O., Standl, E., Cos, X., Heerspink, H. J. L., Itzhak, B., Lalic, N., et al. (2020). Report from the 5th Cardiovascular Outcome Trial (CVOT) summit. Cardiovasc. Diabetology 19 (1), 47. doi:10.1186/s12933-020-01022-7

Schwartz, P. J., Crotti, L., and Insolia, R. (2012). Long-QT Syndrome. Circ. Arrhythm Electrophysiol. 5 (4), 868-877. doi:10.1161/circep.111.962019

Sham, J. S. (1997). Ca2+ Release-Induced Inactivation of Ca2+ Current in Rat Ventricular Myocytes: Evidence for Local Ca2+ Signalling. J. PhysiologyLondon 500 (2), 285-295. doi:10.1113/jphysiol.1997.sp022020

Shimoni, Y., Chuang, M., Abel, E. D., and Severson, D. L. (2004). Genderdependent Attenuation of Cardiac Potassium Currents in Type 2 Diabeticdb/dbmice. J. Physiology-London 555 (2), 345-354. doi:10.1113/ jphysiol.2003.055590

Shimoni, Y., Firek, L., Severson, D., and Giles, W. (1994). Short-Term Diabetes Alters K+ Currents in Rat Ventricular Myocytes. Circ. Res. 74 (4), 620-628. doi:10.1161/01.res.74.4.620

Singh, R. M., Waqar, T., Howarth, F. C., Adeghate, E., Bidasee, K., and Singh, J. (2018). Hyperglycemia-induced Cardiac Contractile Dysfunction in the Diabetic Heart. Heart Fail. Rev. 23 (1), 37-54. doi:10.1007/s10741-0179663-y

Singleton, M. J., German, C., Hari, K. J., Saylor, G., Herrington, D. M., Soliman, E. Z., et al. (2020). QRS Duration Is Associated with All-Cause Mortality in Type 2 Diabetes: The Diabetes Heart Study. J. Electrocardiol. 58, 150-154. doi:10.1016/ j.jelectrocard.2019.11.053

Soltysinska, E., Speerschneider, T., Winther, S. V., and Thomsen, M. B. (2014). Sinoatrial Node Dysfunction Induces Cardiac Arrhythmias in Diabetic Mice. Cardiovasc. Diabetology 13, 122. doi:10.1186/s12933-014-0122-y

Spallone, V., Ziegler, D., Freeman, R., Bernardi, L., Frontoni, S., Pop-Busui, R., et al. (2011). Cardiovascular Autonomic Neuropathy in Diabetes: Clinical Impact, Assessment, Diagnosis, and Management. Diabetes Metab. Res. Rev. 27 (7), 639-653. doi:10.1002/dmrr.1239

Stables, C. L., Musa, H., Mitra, A., Bhushal, S., Deo, M., Guerrero-Serna, G., et al. (2014). Reduced Na+ Current Density Underlies Impaired Propagation in the Diabetic Rabbit Ventricle. J. Mol. Cell Cardiol. 69, 24-31. doi:10.1016/ j.yjmcc.2013.12.031

Suys, B., Heuten, S., De Wolf, D., Verherstraeten, M., de Beeck, L. O., Matthys, D., et al. (2006). Glycemia and Corrected QT Interval Prolongation in Young Type 1 Diabetic Patients: What Is the Relation? Diabetes care 29 (2), 427-429. doi:10.2337/diacare.29.02.06.dc05-1450

Teshima, Y., Takahashi, N., Saikawa, T., Hara, M., Yasunaga, S., Hidaka, S., et al. (2000). Diminished Expression of Sarcoplasmic Reticulum Ca2+-ATPase and Ryanodine Sensitive Ca2+Channel mRNA in Streptozotocin-Induced Diabetic Rat Heart. J. Mol. Cell Cardiol. 32 (4), 655-664. doi:10.1006/jmcc.2000.1107

Torres-Jacome, J., Gallego, M., Rodríguez-Robledo, J. M., Sanchez-Chapula, J. A., and Casis, O. (2013). Improvement of the Metabolic Status Recovers Cardiac Potassium Channel Synthesis in Experimental Diabetes. Acta Physiol. 207 (3), 447-459. doi:10.1111/apha.12043

Tse, G., Lai, E. T., Tse, V., and Yeo, J. M. (2016). Molecular and Electrophysiological Mechanisms Underlying Cardiac Arrhythmogenesis in Diabetes Mellitus. J. Diabetes Res. 2016, 2848759. doi:10.1155/2016/2848759

Tsuchida, K., Watajima, H., and Otomo, S. (1994). Calcium Current in Rat Diabetic Ventricular Myocytes. Am. J. Physiology-Heart Circulatory Physiol. 267 (6), H2280-H2289. doi:10.1152/ajpheart.1994.267.6.h2280

Tsuchida, K., and Watajima, H. (1997). Potassium Currents in Ventricular Myocytes from Genetically Diabetic Rats. Am. J. Physiology-Endocrinology Metab. 273 (4), E695-E700. doi:10.1152/ajpendo.1997.273.4.e695

Turner, J. R., Rodriguez, I., Mantovani, E., Gintant, G., Kowey, P. R., Klotzbaugh, R. J., et al. (2018). Drug-induced Proarrhythmia and Torsade de Pointes: A Primer for Students and Practitioners of Medicine and Pharmacy. J. Clin. Pharmacol. 58 (8), 997-1012. doi:10.1002/jcph.1129 
Veglio, M., Bruno, G., Borra, M., Macchia, G., Bargero, G., D’Errico, N., et al. (2002). Prevalence of Increased QT Interval Duration and Dispersion in Type 2 Diabetic Patients and its Relationship with Coronary Heart Disease: a Population-Based Cohort. J. Intern. Med. 251 (4), 317-324. doi:10.1046/j.1365-2796.2002.00955.x

Veglio, M., Chinaglia, A., and Cavallo Perin, P. (2000). The Clinical Utility of QT Interval Assessment in Diabetes. Diabetes Nutr. Metab. 13 (6), 356-365.

Vicente, J., Zusterzeel, R., Johannesen, L., Mason, J., Sager, P., Patel, V., et al. (2018). Mechanistic Model-Informed Proarrhythmic Risk Assessment of Drugs: Review of the "CiPA" Initiative and Design of a Prospective Clinical Validation Study. Clin. Pharmacol. Ther. 103 (1), 54-66. doi:10.1002/cpt.896

Wang, A., Green, J. B., Halperin, J. L., and Piccini, J. P. (2019). Atrial Fibrillation and Diabetes Mellitus. J. Am. Coll. Cardiol. 74 (8), 1107-1115. doi:10.1016/ j.jacc.2019.07.020

Wang, D. W., Kiyosue, T., Shigematsu, S., and Arita, M. (1995). Abnormalities of $\mathrm{K}+$ and $\mathrm{Ca} 2+$ Currents in Ventricular Myocytes from Rats with Chronic Diabetes. Am. J. Physiology-Heart Circulatory Physiol. 269 (4), H1288-H1296. doi:10.1152/ajpheart.1995.269.4.h1288

Watanabe, M., Yokoshiki, H., Mitsuyama, H., Mizukami, K., Ono, T., and Tsutsui, H. (2012). Conduction and Refractory Disorders in the Diabetic Atrium. Am. J. Physiology-Heart Circulatory Physiol. 303 (1), H86-H95. doi:10.1152/ ajpheart.00010.2012

WHO (2021). Global Report on Diabetes. http://www.who.int.

$\mathrm{Xu}$, J., and Rajaratnam, R. (2017). Cardiovascular Safety of Non-insulin Pharmacotherapy for Type 2 Diabetes. Cardiovasc. Diabetology 16, 18. doi:10.1186/s12933-017-0499-5

Xu, Z., Patel, K. P., and Rozanski, G. J. (1996). Metabolic Basis of Decreased Transient Outward K+ Current in Ventricular Myocytes from Diabetic Rats. Am. J. Physiology-Heart Circulatory Physiol. 271 (5), H2190-H2196. doi:10.1152/ajpheart.1996.271.5.h2190

Yiu, K.-H., and Tse, H.-F. (2008). Hypertension and Cardiac Arrhythmias: a Review of the Epidemiology, Pathophysiology and Clinical Implications. J. Hum. Hypertens. 22 (6), 380-388. doi:10.1038/jhh.2008.10

Yu, P., Hu, L., Xie, J., Chen, S., Huang, L., Xu, Z., et al. (2018). O-GlcNAcylation of Cardiac Nav1.5 Contributes to the Development of Arrhythmias in Diabetic Hearts. Int. J. Cardiol. 260, 74-81. doi:10.1016/j.ijcard.2018.02.099
Zaza, A., and Rocchetti, M. (2013). The Late Na+ Current - Origin and Pathophysiological Relevance. Cardiovasc. Drugs Ther. 27 (1), 61-68. doi:10.1007/s10557-012-6430-0

Zhang, Y., Wang, Y., Yanni, J., Qureshi, M. A., Logantha, S. J. R. J., Kassab, S., et al. (2019). Electrical Conduction System Remodeling in Streptozotocin-Induced Diabetes Mellitus Rat Heart. Front. Physiol. 10 (826). doi:10.3389/fphys.2019.00826

Zhang, Y., Xiao, J., Lin, H., Luo, X., Wang, H., Bai, Y., et al. (2007). Ionic Mechanisms Underlying Abnormal QT Prolongation and the Associated Arrhythmias in Diabetic Rabbits: A Role of Rapid Delayed Rectifier K+ Current. Cell Physiol. Biochem. 19 (5-6), 225-238. doi:10.1159/000100642

Zhang, Y., Xiao, J., Wang, H., Luo, X., Wang, J., Villeneuve, L. R., et al. (2006) Restoring Depressed HERG K+ Channel Function as a Mechanism for Insulin Treatment of Abnormal QT Prolongation and Associated Arrhythmias in Diabetic Rabbits. Am. J. Physiology-Heart Circulatory Physiol. 291 (3), H1446-H1455. doi:10.1152/ajpheart.01356.2005

Zhong, Y., Ahmed, S., Grupp, I. L., and Matlib, M. A. (2001). Altered SR Protein Expression Associated with Contractile Dysfunction in Diabetic Rat Hearts. Am. J. Physiology-Heart Circulatory Physiol. 281 (3), H1137-H1147. doi:10.1152/ajpheart.2001.281.3.h1137

Ziegler, D., Zentai, C. P., Perz, S., Rathmann, W., Haastert, B., Döring, A., et al. (2008) Prediction of Mortality Using Measures of Cardiac Autonomic Dysfunction in the Diabetic and Nondiabetic Population: The MONICA/KORA Augsburg Cohort Study. Diabetes Care 31 (3), 556-561. doi:10.2337/dc07-1615

Conflict of Interest: The authors declare that the research was conducted in the absence of any commercial or financial relationships that could be construed as a potential conflict of interest.

Copyright (c) 2021 Gallego, Zayas-Arrabal, Alquiza, Apellaniz and Casis. This is an open-access article distributed under the terms of the Creative Commons Attribution License (CC BY). The use, distribution or reproduction in other forums is permitted, provided the original author(s) and the copyright owner(s) are credited and that the original publication in this journal is cited, in accordance with accepted academic practice. No use, distribution or reproduction is permitted which does not comply with these terms. 